\title{
Hoe betrouwbaar en valide beoordelen studenten huisartsconsulten?
}

\author{
J. Pols, M.E. Andeweg, P.M. Boendermaker, H.E.P. Bosveld, M. Terluin
}

\begin{abstract}
Samenvatting
Inleiding: Eerder werd onderzoek gedaan naar overeenkomsten en verschillen tussen consulten zoals studenten die in het onderwijs leren en consulten zoals die door huisartsen in de praktijk worden uitgevoerd. Daarbij werd een cohort studenten geneeskunde als onderzoeksassistent ingezet. De vraag rees hoe betrouwbaar en valide beoordelingen door studenten waren.
\end{abstract}

Methode: Tien vrijwilligers uit het cohort beoordeelden met de observatielijst uit het onderzoek vier op video opgenomen consulten. Vier experts deden hetzelfde. De proportie overeenstemming ( $p$ ) en Cohens kappa ( $\kappa)$ werden berekend voor studenten onderling en voor studenten ten opzichte van experts. Op itemniveau werd alleen $p$ berekend; voor de drie fases van het consult en het consult als geheel werden zowel $p$ als $\kappa$ berekend.

Resultaten: Voor de vier consulten samen varieerde $p$ voor de onderlinge overeenstemming van studenten op itemniveau tussen .56 en 1; voor de fases en voor het consult als geheel varieerde $p$ van .74 tot .83 en $\kappa$ van .46 tot .60 . Voor studenten versus experts varieerde $p$ op itemniveau van .68 tot 1; voor de fases en het consult als geheel varieerde $p$ van .83 tot .87 en $\kappa$ van .56 tot .72 .

Conclusie: In dit onderzoek werd de structuur van consulten voldoende betrouwbaar en valide beoordeeld door studenten geneeskunde. De generaliseerbaarheid van dit resultaat wordt beperkt door de onderzoeksopzet. (Pols J, Andeweg ME, Boendermaker PM, Bosveld HEP, Terluin M. Hoe betrouwbaar en valide beoordelen studenten huisartsconsulten? Tijdschrift voor Medisch Onderwijs 2002;21(5):208-213.)

\section{Inleiding}

Studenten geneeskunde en wetenschappelijk onderzoek zijn nauw met elkaar verbonden. Tijdens hun studie leveren studenten als onderzoeker, onderzoeksassistent en object van onderzoek bijdragen aan onderzoek. In het onderzoek dat de directe aanleiding vormt tot dit artikel waren twee studenten (Terluin en Andeweg) onderzoeker en fungeerde een volledig cohort van 225 vierdejaars studenten als onderzoeksassistent. ${ }^{1}$

Het cohort studenten beoordeelde aan de hand van een observatielijst vier consulten van de huisarts bij wie zij in hun vierde studiejaar stage liepen. Op de observatielijst stonden de achttien onderde- len van het consult zoals dat, vanaf het derde studiejaar, wordt getraind tijdens het vaardigheidsonderwijs (tabel 2 en 3 ). De observatielijst bood de studenten per onderdeel de mogelijkheid om aan te geven of het wel of niet voorkwam in de consulten die zij observeerden. Bij het onderzoek waren 157 huisartsen betrokken van wie er 68 tweemaal een student ontvingen.

Het gebruik van een cohort studenten als onderzoeksassistent werd in eerste instantie ingegeven door pragmatische overwegingen: een goedkope manier om snel een grote hoeveelheid consulten in de praktijk te kunnen beoordelen. De uitvoering was echter ook didactisch goed te 
verantwoorden. Een van de doelen van de huisartsstage is dat studenten inzicht krijgen in de manier waarop een huisarts zijn consult opbouwt en wat de verschillen daarvan zijn ten opzichte van consulten in het vaardigheidsonderwijs. De vier geobserveerde consulten vormden de basis voor een gesprek dat zij over dit onderwerp voerden met hun huisarts. Over de waargenomen verschillen en de achtergrond daarvan beantwoordden de studenten drie open vragen.

Van de observatieformulieren werd $84 \%$ geretourneerd met informatie over in totaal 756 consulten. Het onderzoek liet zien dat huisartsen alle achttien onderdelen van het consult gebruiken, maar dat niet alle onderdelen bij elk consult aan bod komen. Bovendien verlopen veel consulten in de praktijk minder gestructureerd dan in het onderwijs. ${ }^{1}$

Bij het onderzoek rees de vraag hoe betrouwbaar en valide studenten de achttien onderdelen van het consult beoordeeld zouden hebben. Dit is geëxploreerd met als uitgangspunt de volgende vragen:

1. In hoeverre vellen studenten onderling vergelijkbare oordelen (hoe betrouwbaar is hun oordeel)?

2. In welke mate stemt het oordeel dat zij vellen overeen met een expertoordeel (hoe valide is hun oordeel)?

\section{Methode}

Vier verschillende consulten zijn elk beoordeeld door tien studenten. De studenten zijn vrijwilligers uit hetzelfde cohort dat het onderzoek bij de huisartsen uitvoerde; zij hebben zichzelf naar aanleiding van een advertentie aangemeld. Voor hun medewerking kregen zij een kleine financiële tegemoetkoming. Zij hebben de vier consulten beoordeeld aan de hand van dezelfde observatielijst die tijdens de huisartsstage is gebruikt (tabel 2 en 3) en ook de opdracht was identiek: beoordeel of consultonderdelen wel of niet voorkomen in de consulten die je observeert.

De consulten zijn op video opgenomen en worden uitgevoerd door dezelfde huisarts. Het zijn gesimuleerde consulten: de patiënten zijn simulatiepatiënten en de spreekkamer is in een studio ingericht. De problemen waarmee de patiënten zich presenteren zijn: pijn in de buik (consult 1 ), pijn in de rechter schouder (consult 2), hoofdpijn op basis van een visusstoornis (consult 3) en slaapstoornis op basis van stress (consult 4).

Over de videoconsulten is een expertoordeel samengesteld door vier van de vijf auteurs: twee artsen die betrokken zijn geweest bij de ontwikkeling en uitvoering van het onderwijs rond consultvoering en twee studenten die door hun intensieve betrokkenheid bij het eerder genoemde onderzoek als expert beschouwd konden worden. Zij hebben onafhankelijk van elkaar beoordeeld of de achttien consultonderdelen wel of niet voorkwamen in de videoconsulten. Na afloop zijn de oordelen vergeleken en waar geen overeenstemming bestond, zijn de verschillende opvattingen besproken en is een gezamenlijk standpunt ingenomen.

Als maat voor de beoordelaarsbetrouwbaarheid is gebruik gemaakt van de proportie overeenstemming en van Cohens kappa. Bij de proportie overeenstemming wordt niet gecorrigeerd voor de overeenstemming op basis van toeval, bij Cohens kappa gebeurt dat wel. Beide maten zijn zowel per consult berekend als voor de vier consulten samen. De proportie overeenstemming is berekend voor elk onderdeel van de observatielijst, voor elke consultfase en voor het volledige consult. Cohens kappa kan niet per onderdeel berekend worden en is daarom alleen berekend voor elke consultfase en voor het volledige consult. 
Bij het vaststellen van de gewenste beoordelaarsovereenstemming is er rekening mee gehouden dat men bij studies met een explorerend karakter (zoals wij dat uitvoerden) soepeler mag zijn ten aanzien van de betrouwbaarheidseisen dan bij studies met een toetsend karakter (bijvoorbeeld bij examens). ${ }^{2}$

In de literatuur worden geen richtlijnen gegeven ten aanzien van de wenselijke proportie overeenstemming. Gezien het explorerend karakter van ons onderzoek hebben wij de grens voor een acceptabele overeenstemming gelegd bij $\geq .66$.

Voor een kwalitatief oordeel over de waarden van kappa is gebruik gemaakt van de indeling volgens Landis en Koch. ${ }^{3}$

Tabel 1. Interpretatie van waarden van Cohens kappa naar Landis en Koch.

\begin{tabular}{ll}
\hline $\mathbf{k}$ & interpretatie \\
\hline$<.00$ & poor \\
$.00-.20$ & slight \\
$.21-.40$ & fair \\
$.41-.60$ & moderate \\
$.61-.80$ & substantial \\
$.81-1.00$ & almost perfect \\
\hline
\end{tabular}

In de literatuur wordt aangegeven dat een $\kappa$ van .60 (substantial) als een minimum moet worden beschouwd wil men over een acceptabele beoordelaarsovereenstemming spreken, maar liever ziet men een $\kappa$ van .80 of hoger (almost perfect). ${ }^{4}$ Daarbij wordt echter uitgegaan van studies met een toetsend karakter. Voor ons onderzoek leggen wij de grens daarom bij $\geq .41$ (moderate).

\section{Resultaten}

\section{Onderlinge overeenstemming (tabel 2)}

Voor de achttien onderdelen van het consult varieert de gemiddelde proportie overeenstemming bij de individuele consulten tussen .44 en 1 en voor de vier con- sulten samen tussen .56 en 1 .

Per consultfase varieert de proportie overeenstemming bij de individuele consulten van .63 tot .91 en voor de vier consulten samen tussen .74 en .83. Per consultfase varieert de waarde van kappa voor de individuele consulten van poor tot substantial, voor de vier consulten samen is de waarde moderate.

Voor het gehele consult varieert de proportie overeenstemming van .71 tot .82 en is de waarde van kappa moderate. Voor de vier consulten samen is de proportie overeenstemming .78 en is de waarde van kappa moderate.

\section{Overeenstemming van studenten met ex-} pertoordeel (tabel 3)

Voor de achttien onderdelen van het consult varieert de gemiddelde proportie overeenstemming bij de individuele consulten tussen .4 en 1 en voor de vier consulten samen tussen .68 en 1 .

Per consultfase varieert de proportie overeenstemming bij de individuele consulten van .78 tot .95 en voor de vier consulten samen tussen .83 en .88 .

Per consultfase varieert de waarde van kappa voor de individuele consulten van poor tot almost perfect. Voor de vier consulten samen is de waarde van kappa voor fase 1 en 2 moderate, voor fase 3 substantial.

Voor het gehele consult varieert de proportie overeenstemming van .82 tot .87 . De waarde van kappa is voor consult 1 moderate en voor consult 2, 3 en 4 substantial. Voor de vier consulten samen is de proportie overeenstemming .85 en is de waarde van kappa substantial.

\section{Discussie}

De grootste interesse ging uit naar de beoordelaarsovereenstemming bij de achttien onderdelen van het consult, omdat juist dat onderzocht is bij de vergelijking 
Tabel 2. Mate van overeenstemming tussen studenten onderling bij de beoordeling van videoconsulten; weergegeven als totale proportie overeenstemming met tussen haakjes de waarde van kappa.

\begin{tabular}{|c|c|c|c|c|c|c|}
\hline & & & & onsultnun & nmer & \\
\hline & & 1 & 2 & 3 & 4 & $1-4$ \\
\hline item 1 & contactreden & 1 & .80 & 1 & 1 & .95 \\
\hline item 2 & aanleiding & 1 & .80 & .46 & 1 & .82 \\
\hline item 3 & hulpvraag & .64 & .46 & .54 & .80 & .61 \\
\hline item 4 & hoofdklacht & 1 & 1 & 1 & .80 & .95 \\
\hline item 5 & aard van de klacht & .46 & .80 & 1 & .46 & .68 \\
\hline item 6 & lokalisatie van de klacht & 1 & 1 & .80 & .10 & .73 \\
\hline item 7 & ernst van de klacht & .46 & 1 & .80 & .64 & .73 \\
\hline item 8 & chronologie van de klacht & .80 & .64 & .46 & .80 & .68 \\
\hline item 9 & ontstaan van de klacht & .46 & 1 & .46 & .80 & .68 \\
\hline item 10 & beïnvloeding van de klacht & .54 & .64 & .44 & .64 & .57 \\
\hline item 11 & bevinding & 1 & .46 & 1 & .80 & .82 \\
\hline item 12 & hypothesetoetsing & 1 & .64 & 1 & .44 & .77 \\
\hline item 13 & lichamelijk onderzoek & 1 & 1 & 1 & 1 & 1 \\
\hline item 14 & samenvatting & 1 & 1 & 1 & .54 & .89 \\
\hline item 15 & uitleg diagnose & .64 & .80 & .80 & .64 & .72 \\
\hline item 16 & beleid & 1 & 1 & 1 & .80 & .95 \\
\hline item 17 & bespreking uitvoering beleid & 1 & 1 & .54 & 1 & .89 \\
\hline item 18 & afronding & .80 & .54 & .46 & .44 & .56 \\
\hline fase 1 & item $1 \mathrm{t} / \mathrm{m} 4$ & $.91(.09)$ & $.77(.50)$ & $.75(.44)$ & $.90(-.03)$ & $.83(.47)$ \\
\hline fase 2 & item 5 t/m 13 & $.75(.27)$ & $.80(.50)$ & $.77(.55)$ & $.63(.42)$ & $.74(.46)$ \\
\hline fase 3 & item 14 t/m 18 & $.89(.71)$ & $.87(.00)$ & $.76(.49)$ & $.68(.34)$ & $.80(.60)$ \\
\hline consult & item $1 \mathrm{t} / \mathrm{m} 18$ & $.82(.44)$ & $.81(.55)$ & $.76(.51)$ & $.71(.47)$ & $.78(.51)$ \\
\hline
\end{tabular}

van consulten van huisartsen met die in het vaardigheidsonderwijs. ${ }^{1}$ De tabellen laten zien dat er tussen de beoordelaars verschillen bestaan in overeenstemming over onderdelen van consulten, maar ook voor hetzelfde onderdeel van verschillende consulten. Het ene consultonderdeel is blijkbaar eenduidiger te beoordelen dan het andere en dat geldt ook voor hetzelfde consultonderdeel bij verschillende consulten. Bij het onderzoek onder huisartsen werd de studenten gevraagd om vier consulten van hun huisarts te beoordelen, daarom is het gerechtvaardigd om ook nu te kijken naar de hoogte van de beoordelaarsbetrouwbaarheid voor de vier consulten samen. Voor de studenten onderling varieert de proportie overeenstemming bij de verschillende items van < .56 tot 1 (negen van de achttien items $<.75$; drie van de achttien items $<$.66) en tussen studenten en experts van .68 tot 1 (bij drie van de achttien items $<.75$, geen lager dan .68). Dat betekent dat de betrouwbaarheid van de beoordeling van de consultonderdelen door de studenten acceptabel is, met uitzondering van de drie items (3, 10 en 18) waarbij de beoordelaarsovereenstemming voor de studenten onderling lager is dan .66. 
Tabel 3. Mate van overeenstemming tussen studenten en experts bij de beoordeling van videoconsulten; weergegeven als totale proportie overeenstemming met tussen haakjes de waarde van kappa.

\begin{tabular}{|c|c|c|c|c|c|c|}
\hline & & \multicolumn{5}{|c|}{ consultnummer } \\
\hline & & 1 & 2 & 3 & 4 & $1-4$ \\
\hline item 1 & contactreden & 1 & .90 & 1 & 1 & .98 \\
\hline item 2 & aanleiding & 1 & .90 & .40 & 1 & .83 \\
\hline item 3 & hulpvraag & .80 & .60 & .70 & .90 & .75 \\
\hline item 4 & hoofdklacht & 1 & 1 & 1 & .90 & .98 \\
\hline item 5 & aard van de klacht & .40 & .90 & 1 & .60 & .73 \\
\hline item 6 & lokalisatie van de klacht & 1 & 1 & .90 & 1 & .98 \\
\hline item 7 & ernst van de klacht & .60 & 1 & .90 & .80 & .83 \\
\hline item 8 & chronologie van de klacht & .90 & .80 & .60 & .90 & .80 \\
\hline item 9 & ontstaan van de klacht & .60 & 1 & .60 & .90 & .78 \\
\hline item 10 & beïnvloeding van de klacht & .70 & .80 & .50 & .80 & .70 \\
\hline item 11 & bevinding & 1 & .40 & 1 & .90 & .83 \\
\hline item 12 & hypothesetoetsing & 1 & .80 & 1 & .50 & .83 \\
\hline item 13 & lichamelijk onderzoek & 1 & 1 & 1 & 1 & 1 \\
\hline item 14 & samenvatting & 1 & 1 & 1 & .70 & .93 \\
\hline item 15 & uitleg diagnose & .80 & .90 & .90 & .80 & .85 \\
\hline item 16 & beleid & 1 & 1 & 1 & .90 & .98 \\
\hline item 17 & bespreking uitvoering beleid & 1 & 1 & .70 & 1 & .93 \\
\hline item 18 & afronding & .90 & .70 & .60 & .50 & .68 \\
\hline fase 1 & item 1 t/m 4 & $.95(.00)$ & $.85(.65)$ & $.78(.45)$ & $.95(.00)$ & $.88(.56)$ \\
\hline fase 2 & item $5 \mathrm{t} / \mathrm{m} 13$ & $.80(.30)$ & $.86(.63)$ & $.83(.66)$ & $.82(.60)$ & $.83(.59)$ \\
\hline fase 3 & item $14 \mathrm{t} / \mathrm{m} 18$ & $.94(.83)$ & $.92(.78)$ & $.84(.62)$ & $.78(.54)$ & $.87(.72)$ \\
\hline consult & item $1 \mathrm{t} / \mathrm{m} 18$ & $.87(.51)$ & $.87(.67)$ & $.82(.62)$ & $.84(.64)$ & $.85(.63)$ \\
\hline
\end{tabular}

De validiteit van de beoordelingen door de studenten is over de hele linie acceptabel, de mate van overeenstemming tussen studenten en experts is nooit lager dan .68 . Betrouwbaarheid en validiteit van het studentenoordeel over de fases van het consult en het volledige consult zijn nooit lager dan .74 en dus zeker acceptabel.

Ook op basis van de waarden van kappa voor de vier consulten samen zijn betrouwbaarheid en validiteit van het oordeel van de studenten acceptabel. Bij de waarden van kappa voor de individuele consulten doet zich de eigenaardigheid voor dat de proportie overeenstemming hoog kan zijn met een lage of negatieve waarde van kappa (zie bijvoorbeeld in tabel 2 fase 1 van consult 4: proportie overeenstemming .90, kappa -.03). Over de achtergronden daarvan en de problemen die dit fenomeen oplevert bij het gebruik van Cohens kappa berichten wij separaat. 5

Ons onderzoek laat zien dat studenten zowel wat betreft betrouwbaarheid als wat betreft validiteit in staat zijn tot een acceptabele beoordeling van consulten van huisartsen. Daarbij moet de kanttekening worden gemaakt dat dat geldt voor de condities die ook in het onderzoek bij huisartsen golden: als vier consulten wor- 
den geobserveerd. Voor individuele consulten is de situatie minder gunstig.

Gezien de geringe omvang van onze onderzoeksgroep mogen deze resultaten niet worden gegeneraliseerd naar het hele cohort studenten dat wij als onderzoeksassistent gebruikten. De generaliseerbaarheid van onze resultaten wordt verder beperkt doordat de steekproef van studenten niet aselect was.

In het onderzoek bij huisartsen bleek dat een cohort studenten bruikbaar is als onderzoeksassistent voor observationeel onderzoek naar de dagelijkse praktijk van consulten. ${ }^{1}$ Of zij ook betrouwbare en valide observaties deden kan op basis van het hier beschreven onderzoek niet worden vastgesteld.

\section{Dankbetuiging}

Dr. P. Ram danken wij hartelijk voor het ter beschikking stellen van de video-opnames.

\section{Literatuur}

1. Terluin M, Andeweg ME, Boendermaker PM, Pols J. De structuur van een consult - onderwijs en praktijk. Tijdschrift voor Medisch Onderwijs 2002; 21(2):50-6
2. Groot AD de. Methodologie. Grondslagen van onderzoek en denken in de gedragswetenschappen. $12^{\text {de }}$ druk. Assen: Van Gorcum; 1994.

3. Landis JR, Koch GG. The measurement of observer agreement for categorical data. Biometrics 1977; 33(1):159-74.

4. Eggen TJHM, Sanders PF. Psychometrie in de praktijk. Arnhem: Cito Instituut voor Toetsontwikkeling; 1993.

5. Pols J, Bosveld HEP. Beoordelaarsbetrouwbaarheid (niet) meten met behulp van Cohens kappa? Geacctepteerd voor publicatie in Tijdschrift voor Medisch Onderwijs.

De auteurs:

Drs. J. Pols, arts-onderwijskundige, Onderwijsinstituut, Afdeling Onderwijsontwikkeling en Kwaliteitszorg, Faculteit der Medische Wetenschappen, Rijksuniversiteit Groningen.

Drs. M.E. Andeweg, AGNIO, Refaja Ziekenhuis, Stadskanaal.

Drs. P.M. Boendermaker, huisarts, Disciplinegroep Huisartsgeneeskunde, Faculteit der Medische Wetenschappen, Rijksuniversiteit Groningen.

Drs. H.E.P. Bosveld, methodoloog, Disciplinegroep Huisartsgeneeskunde, Faculteit der Medische Wetenschappen, Rijksuniversiteit Groningen.

Drs. M. Terluin, AGNIO, Refaja Ziekenhuis, Stadskanaal.

Correspondentieadres:

J. Pols, arts-onderwijskundige, Onderwijsinstituut, Faculteit der Medische Wetenschappen, Rijksuniversiteit Groningen, A. Deusinglaan 1, 9713 AV Groningen.

Tel.: 050-3637629, fax:050-3633865, j.pols@med.rug.nl.

\section{Summary}

Introduction: In a previous study we investigated similarities and dissimilarities between the consultation as students are taught to conduct it in medical school and real consultations as conducted by general practitioners in dayto-day practice. In the earlier study a cohort of medical students observed consultations conducted by general practitioners. In this paper we explore the reliability and validity of the students' observations.

Method: Ten volunteers from the original student cohort observed four videotaped consultations and recorded their findings on a checklist. This checklist was identical to the one used in the previous study. The consultations were also observed by four experts who recorded their findings on the same checklist. The proportion of observer agreement ( $p$ ) and Cohen's kappa ( $(\kappa)$ were calculated for observer agreement between students and between students and experts. For the individual checklist items $p$ was calculated and both $p$ and $\kappa$ were calculated for the three phases in the consultation and the consultation as a whole.

Results: For the four consultations together the proportion observer agreement between students for the items of the checklist varied between .56 and 1. For the phases and for the consultation as a whole, p varied between .74 and .83 and $\kappa$ between .46 and .60 . The proportion agreement between students and experts for the items of the checklist varied between .68 and 1. For the phases and for the consultation as a whole p varied between .83 and .87 and $\kappa$ between .56 and .72 .

Conclusion: In this study the observation of consultations by students was sufficiently reliable and valid. Generalizations cannot be made, however, due to the design of the study. (Pols J, Andeweg ME, Boendermaker PM, Bosveld HEP, Terluin M. How reliable and valid are students' observations of consultations in general practice? Dutch Journal of Medical Education 2002;21(5):208-213.) 